\title{
Newly impaired glucose metabolism and prognosis after percutaneous revascularization
}

\author{
Manuel F. Jiménez-Navarro ${ }^{1,2}$, Julia Fernández-Pastor ${ }^{1}$, Lourdes Garrido-Sánchez ${ }^{3,4}$, \\ Maria J. Molina-Mora ${ }^{1}$, Carmen Ortiz-García ${ }^{5}$, Juan H. Alonso-Briales ${ }^{1}$, \\ Alejandro Pérez-Cabeza ${ }^{1}$, Jose M. Hernández-Garcia ${ }^{1}$, \\ Eduardo de Teresa-Galván ${ }^{1,2}$, Francisco J. Tinahones ${ }^{2,3,4}$
}

${ }^{1}$ Unidad de Gestion Clinica del Corazón, Instituto de Biomedicina de Málaga (IBIMA), Hospital Universitario Virgen de la Victoria, University of Malaga, Malaga, Spain, Red de Investigación Cardiovascular (RIC)

${ }^{2}$ Medicine Department, School of Medicine, University of Malaga, Spain

${ }^{3}$ Unidad de Gestion Clinica de Endocrinogía y Nutrición, Instituto de Investigaciones Biomédicas de Málaga (IBIMA), Virgen de la Victoria University Hospital, Malaga, Spain ${ }^{4}$ CIBEROBN, Malaga, Spain

${ }^{5}$ Laboratory Service, Virgen de la Victoria University Hospital, Malaga, Spain

\begin{abstract}
Background: Clinical practice guidelines recommend ad hoc screening of diabetes in patients admitted for macrovascular disease; however, these recommendations are rarely followed in real practice. This study was undertaken to assess whether impaired glucose metabolism, newly diagnosed after percutaneous coronary intervention (PCI) or known diabetes, provides prognostic information.
\end{abstract}

Methods: We studied 374 patients who underwent PCI. An oral glucose tolerance test was carried out in the known non-diabetic patients with fasting glucose $<7 \mathrm{mmol} / \mathrm{L}$.

Results: Eighty-one percent of the patients presented impaired glucose metabolism, from which $35.3 \%$ were previously diagnosed with diabetics, $21.4 \%$ were newly detected diabetics, and $24.3 \%$ were pre-diabetics. After a mean follow-up of $35.8 \pm 13.4$ months, only a known history of diabetes was an independent predictor of revascularization $(O R=2.03, p=0.025)$, non-fatal acute myocardial infarction $(O R=2.70, p=0.029)$ and readmission due to heart failure during the follow-up $(O R=3.82, p=0.022)$.

Conclusions: Screening for impaired glucose metabolism after PCI permits the detection of a high proportion of patients with abnormal glucose regulations. However, previously known diabetes remains the only independent predictor of cardiovascular events in the follow-up. (Cardiol J 2015; 22, 1: 44-51)

Key words: diabetes, impaired glucose metabolism, percutaneous coronary intervention

Address for correspondence: Dr Manuel F. Jiménez Navarro, Unidad de Gestion Clinica del Corazón, Instituto de Biomedicina de Málaga (IBIMA), Hospital Universitario Virgen de la Victoria, Málaga, Universidad de Málaga, Spain. RIC investigators, Campus Universitario de Teatinos s/n. ZIP Code: 29010. Málaga, Spain, tel: +34951032389, fax: +35951032618, e-mail: mjimeneznavarro@gmail.com

AND

Dr Lourdes Garrido-Sanchez, Unidad de Gestion Clinica de Endocrinogía y Nutrición, Instituto de Investigaciones Biomédicas de Málaga (IBIMA), Virgen de la Victoria University Hospital, Málaga, Spain, Campus Universitario de Teatinos s/n. ZIP Code: 29010. Málaga, Spain, tel: +34 951032648/+34 977295823, e-mail: lourgarrido@gmail.com 


\section{Introduction}

According to Euro Heart Survey Program [1] and other epidemiological data, the prevalence of diabetes mellitus (DM) in adults increased, the number of individuals affected with DM also increased and other data show a consistent increase of the number of people with DM and cardiovascular disease (CVD) [1,2]. There is also an increased number of diabetics receiving percutaneous coronary intervention (PCI) [3]. The rising prevalence of DM is followed by an increasing prevalence of CVD morbidity and mortality. In the last decade, all-cause and cause specific mortality rates declined in all patients, although not in patients with DM [2]. These data suggest that increases in DM rates threaten the long-established nationwide trend towards reduced coronary artery events.

Diabetes and carbohydrate intolerance increase cardiovascular risk $[4,5]$. Indeed, Euro Heart Survey data show a high proportion of impaired glucose metabolism, which could influence prognosis [6] among patients suffering from ischemic heart disease. This is why European guidelines [7], unlike the proposals of the American Diabetes Association (ADA) [8], recommend ad hoc screening of patients admitted for macrovascular disease by means of an oral glucose tolerance test that provides more precise information about fasting glucose. Although it is accepted as a valid option for the diagnosis of diabetes, glycated hemoglobin $\left(\mathrm{HbA}_{1 \mathrm{c}}\right)$, when used in isolation, may give incorrect results under certain conditions, which is why recommendations are fundamentally based on carrying out an oral glucose tolerance test (OGTT) $[7,9]$. For the diagnosis of diabetes, the OGTT is a more sensitive and better predictor of CVD than fasting glucose [9-11]. Nevertheless, despite being the best tool available, it does not wholly fulfil the characteristics of speed, simplicity, and reproducibility that are desirable in every screening test, and in habitual clinical practice guidelines are rarely followed.

On the other hand, the significance of heart disease in our population in absolute terms is well-known, as is how coronary revascularization procedures have shown prognostic improvement for many CVD in global terms and for diabetics in particular [12]. Therefore, given the large number of procedures that are carried out, this could be a suitable occasion for ad hoc screening for impaired glucose metabolism.

The objective of this study was to assess whether impaired glucose metabolism, newly detected, versus known diabetics with coronary artery disease admitted for PCI provides prognostic information in terms of cardiovascular events and mortality during follow-up compared to a previously recognized diagnosis of diabetes.

\section{Methods}

\section{Population}

The patients included in this study underwent PCI in the context of stable angina with inducible ischemia or symptoms refractory to medical treatment, or with acute coronary syndrome (ACS) (with or without ST segment elevation) in our center $(\mathrm{n}=377)$. Unstable angina and non-ST-elevation ACS (NSTE-ACS) were defined by electrocardiographic ST segment depression or prominent T-wave inversion and/or positive biomarkers of necrosis in the absence of ST-segment elevation and in an appropriate clinical setting (chest discomfort or anginal equivalent). ST-elevation myocardial infarction (STEMI) was defined by the presence of ischemic symptoms and persistent electrocardiographic ST segment elevation.

Exclusion criteria: hemodynamic instability (Killip III-IV), post-PCI transferral of the patient to the hospital of origin, treatment with glucose metabolism modifying drugs (glucocorticoids, thiazide diuretics, levothyroxine and niacin), any allergy to dual antiplatelet therapy, patient's refusal or failure to sign informed consent.

\section{Study protocol}

A prospective longitudinal observational study was designed. All patients underwent diagnostic therapeutic cardiac catheterization via the femoral or radial artery using the Seldinger technique, and the SYNTAX score [13] was applied to estimate the extent and complexity of coronary heart disease. The score was independently determined by 2 specialists in hemodynamics. As defined in the inclusion criteria, all patients underwent PCI while admitted. Left ventricular ejection fraction (LVEF) was quantified by means of a contrast ventriculography and/or via echocardiography, using Simpson's rule (Acuson Sequoya, Siemens AG, Munich, Germany). All of the patients were informed about the nature of the study and gave their written consents, and the study was reviewed and approved by the Ethics and Research Committees of our hospital.

\section{Definition of glucometabolic status}

Among the included patients, we considered known diabetics to be those who had a previously 
recognized diagnosis of this pathology, regardless of the use of pharmacological treatment. Fasting plasma glucose (after $8 \mathrm{~h}$ with no calorie intake) and levels of $\mathrm{HbA}_{1 \mathrm{c}}$ were determined for these known diabetics $(n=132)$.

Fasting plasma glucose for patients with no previous diagnosis of diabetes was determined the morning after percutaneous coronary revascularization. Patients with fasting glucose $<7 \mathrm{mmol} / \mathrm{L}$ were given an OGTT using $75 \mathrm{~g}$ of anhydrous glucose, with fasting plasma glucose determined before the test and plasma glucose $2 \mathrm{~h}$ after intake. Thus, it was possible to categorize the patients with no previously recognized diagnosis of diabetes as follows, in accordance with American Diabetes Association (ADA) classifications [8]:

- Patients with normal glucose metabolism: those with fasting plasma glucose $<5.6 \mathrm{mmol} / \mathrm{L}$, plasma glucose $<7.8 \mathrm{mmol} / \mathrm{L} 2 \mathrm{~h}$ after the $\operatorname{OGTT}(\mathrm{n}=71)$;

- Pre-diabetics: those with fasting plasma glucose of 5.6-6.9 mmol/L (impaired fasting glucose) or plasma glucose $7.8-11.0 \mathrm{mmol} / \mathrm{L} 2 \mathrm{~h}$ post-intake (intolerance to glucose) $(n=91)$;

- Newly detected diabetics: patients were considered as such if they had no known history of diabetes and presented a fasting plasma glucose $\geq 7 \mathrm{mmol} / \mathrm{L}$ or plasma glucose $\geq 11.1 \mathrm{mmol} / \mathrm{L} 2 \mathrm{~h}$ post-intake $(\mathrm{n}=65)$.

\section{Follow-up}

Clinical follow-up of all included patients was carried out in person or by phone. During follow-up we recorded events, which included the need for coronary revascularization, readmission due to unstable angina or non-fatal acute myocardial infarction (AMI) or heart failure (HF), and cardiovascular mortality. A record was also kept of the incidence of cerebrovascular accidents and mortality due to any cause during follow-up.

\section{Statistical analysis}

Continuous variables are expressed as a mean \pm standard deviation and categorical variables as percentages. Normal distribution of quantitative variables was checked using the Shapiro-Wilk test. In the case of normality, Levene's test was applied to compare variance; where variances were equal, Student's t-test was used to compare the averages; if variances were different, Welch's test was used for the comparison. In the absence of normality, the Mann-Whitney test was applied to compare averages. We used the ANOVA test to compare quantitative variable means between more than two groups. The $\chi^{2}$ test was used to compare qualitative variables. A two sided value of $p<0.05$ was considered significant. Multivariate analysis was made using a multiple logistic regression model to identify independent variables predictive of adverse events in follow-up. The model included those variables that reached a statistical significance level of 0.15 in the univariate analysis and known variables related with prognosis. The odds ratio $(\mathrm{OR})$ and $95 \%$ confidence intervals $(\mathrm{CI})$ were calculated from the parameters estimated by the regression model. All statistical analysis was made using the SPSS program (version 11.0, SPSS Inc., Chicago, IL, USA).

\section{Results}

\section{Characteristics of the population}

Three hundred and seventy-seven patients met the criteria during the inclusion period and agreed to participate in the study and 3 were excluded due to deviations in the intake protocol which prevented definition of their glucometabolic status, thus 374 patients were finally included in the analysis.

The mean age of the sample was $62.67 \pm$ \pm 10.72 years, and $77.3 \%$ were male. The indication for coronarography was NSTE-ACS in $52.7 \%$ of patients, with ST elevation (STE-ACS) in $27.3 \%$ and stable stress angina in $19.8 \%$.

The $81 \%$ of included patients presented impaired glucose metabolism, of which percentage $35.29 \%$ were previously diagnosed diabetics, $21.39 \%$ newly detected diabetics and $24.33 \%$ pre-diabetics.

Basal characteristics of the patients, categorized according to the presence of impaired glucose metabolism are shown in Table 1 . The previously recognized diabetic patients were older, with a lower percentage of men, and the predominant indication for coronarography was NSTE-ACS. With regard to pharmacological treatment, the diabetic patients more frequently received glycoprotein IIb/IIIa inhibitors (53\% of recognized diabetic patients vs. $28.1 \%$ of the total of patients with no known history of DM, p < 0.0001), and angiotensin-converting enzyme inhibitors or angiotensin II receptor antagonists $(77.3 \%$ of known diabetics vs. $62 \%$ of patients with no known history of DM, $\mathrm{p}=0.003$ ) without the existence of significant differences in other treatments. The average SYNTAX score for the total of patients was $11.29 \pm 7.73$. When comparisons were made of the glucometabolic status between the four groups, the score increased in pa- 
Table 1. Baseline characteristics.

\begin{tabular}{|c|c|c|c|c|c|c|}
\hline & $\begin{array}{l}\text { Normal } \\
(n=71)\end{array}$ & $\begin{array}{l}\text { Pre-diabetes } \\
\qquad(\mathrm{n}=91)\end{array}$ & $\begin{array}{c}\text { Newly } \\
\text { detected } \\
\text { diabetes } \\
(n=80)\end{array}$ & $\begin{array}{l}\text { Known } \\
\text { diabetes } \\
\text { (n=132) }\end{array}$ & p* & $\mathbf{p}^{\dagger}$ \\
\hline Age [years] & $55.95 \pm 10.93$ & $62.98 \pm 10.91$ & $63.01 \pm 9.79$ & $66.64 \pm 9.14$ & $<0.0001$ & $<0.0001$ \\
\hline Gender (male) & $95.8 \%$ & $78.0 \%$ & $81.3 \%$ & $64.4 \%$ & $<0.0001$ & $<0.0001$ \\
\hline Hypertension & $59.2 \%$ & $49.5 \%$ & $53.8 \%$ & $70.5 \%$ & 0.009 & 0.002 \\
\hline Smoker & $49.3 \%$ & $30.8 \%$ & $46.3 \%$ & $40.9 \%$ & 0.077 & $<0.0001$ \\
\hline $\mathrm{HbA}_{1 \mathrm{c}}[\%]$ & $5.02 \pm 0.43$ & $5.05 \pm 0.47$ & $5.28 \pm 0.59$ & $5.32 \pm 0.71$ & 0.020 & 0.010 \\
\hline Dyslipidemia & $56.3 \%$ & $50.5 \%$ & $45 \%$ & $60.6 \%$ & 0.137 & 0.059 \\
\hline Chronic kidney disease & $0 \%$ & $6.6 \%$ & $5 \%$ & $6.1 \%$ & 0.197 & 0.400 \\
\hline Prior IHD & $32.4 \%$ & $33 \%$ & $40 \%$ & $47.7 \%$ & 0.076 & 0.017 \\
\hline \multicolumn{7}{|c|}{ Prior coronary revascularization: } \\
\hline Percutaneous & $11.3 \%$ & $9.9 \%$ & 10.0 & 12.9 & 0.510 & 0.100 \\
\hline Surgical & $4.2 \%$ & $2.2 \%$ & 3.8 & 3.8 & & \\
\hline Both & $0 \%$ & $0 \%$ & 1.3 & 3.8 & & \\
\hline \multicolumn{7}{|l|}{ Clinical presentation: } \\
\hline Stable angina & $12.7 \%$ & $15.4 \%$ & $26.3 \%$ & $21.2 \%$ & $<0.0001$ & $<0.0001$ \\
\hline NSTE-ACS & $45.1 \%$ & $59.3 \%$ & $38.8 \%$ & $60.6 \%$ & & \\
\hline STE-ACS & $42.3 \%$ & $25.3 \%$ & $35.0 \%$ & $16.7 \%$ & & \\
\hline \multicolumn{7}{|l|}{ In hospital treatment: } \\
\hline IIb/IIla inhibitors & $36.6 \%$ & $24.2 \%$ & $25 \%$ & $53.8 \%$ & $<0.0001$ & $<0.0001$ \\
\hline Beta-blockers & $84.5 \%$ & $82.4 \%$ & $86.3 \%$ & $86.4 \%$ & 0.854 & 0.590 \\
\hline ACEI/ARB & $63.4 \%$ & $60.4 \%$ & $62.5 \%$ & $77.3 \%$ & 0.026 & 0.030 \\
\hline Statins & $88.7 \%$ & $82.4 \%$ & $82.5 \%$ & $84.1 \%$ & 0.685 & 0.950 \\
\hline Syntax score & $9.97 \pm 6.20$ & $9.88 \pm 6.63$ & $10.92 \pm 7.54$ & $13.17 \pm 8.88$ & 0.004 & 0.001 \\
\hline $\begin{array}{l}\text { Left ventricular dysfun- } \\
\text { ction (LVEF }<50 \% \text { ) }\end{array}$ & $37.5 \%$ & $31.8 \%$ & $29.5 \%$ & $41.9 \%$ & 0.319 & 0.012 \\
\hline \multicolumn{7}{|l|}{ Stent: } \\
\hline Bare metal stent & $18.3 \%$ & $23.1 \%$ & $17.5 \%$ & $4.5 \%$ & & \\
\hline Drug eluting stent & $76.1 \%$ & $67.0 \%$ & $76.3 \%$ & $91.7 \%$ & 0.003 & $<0.0001$ \\
\hline Both & $5.6 \%$ & $8.8 \%$ & $6.3 \%$ & $3.8 \%$ & & \\
\hline
\end{tabular}

${ }^{*} p$ value in comparison between the four groups; ${ }^{\dagger} p$ value of the comparison between known diabetics and all the remaining patients; IHD - ischemic heart disease; NSTE-ACS - non-ST-elevation acute coronary syndrome; STE-ACS - ST-elevation acute coronary syndrome; ACEI - angiotensin converting enzyme inhibitors; ARB — angiotensin receptors blockers; LVEF — left ventricular ejection fraction

rallel with the presence of impaired glucose metabolism in a statistically significant way $(\mathrm{p}=0.004)$; $85.3 \%$ of patients received drug-eluting stents, reaching $91.7 \%$ among diabetic patients. None of the included patients died while admitted and discharged after an average stay of $5.01 \pm 3.74$ days.

\section{The prognostic implications of impaired glucose metabolism}

After a mean follow-up of $35.84 \pm 13.43$, during which months there was a loss of $12(3.20 \%)$ patients, $47(13 \%)$ patients required a new percutaneous or surgical revascularization, there were $32(8.8 \%)$ readmissions for unstable angina,
$21(5.8 \%)$ for non-fatal AMI, 15 (4.1\%) for HF, and $13(3.6 \%)$ deaths attributable to cardiovascular causes. Seven (1.9\%) patients suffered a non-fatal cerebrovascular accident and global mortality was $4.7 \%$. The events during follow-up in the different glucose metabolism categories are shown in Table 2. Previously known diabetic patients had higher rates of complications than non-known diabetic patients. We appreciate a growing trend towards the incidence of readmission for HF, in parallel with the magnitude of glucose metabolism impairment (8.1\% of known diabetics, $3.8 \%$ of newly detected diabetic patients, $2.2 \%$ of pre-diabetic patients and $0 \%$ of patients with normal glucose metabolism, 
Table 2. Events on follow-up.

\begin{tabular}{lcccccc}
\hline & $\begin{array}{c}\text { Normal } \\
\text { (n=69) }\end{array}$ & $\begin{array}{c}\text { Pre-diabetes } \\
(\mathbf{n}=90)\end{array}$ & $\begin{array}{c}\text { Newly detected } \\
\text { diabetes } \\
\text { (n= 79) }\end{array}$ & $\begin{array}{c}\text { Known diabetes } \\
\text { (n = 124) }\end{array}$ & $\mathbf{p}^{*}$ & $\mathbf{p}^{\dagger}$ \\
\hline Revascularization & $10.1(7)$ & $6.7(6)$ & $13.9(11)$ & $18.5(23)$ & 0.06 & 0.023 \\
Unstable angina & $8.7(6)$ & $6.7(6)$ & $8.9(7)$ & $10.5(13)$ & 0.810 & 0.420 \\
Non-fatal AMI & $4.3(3)$ & $3.3(3)$ & $3.8(3)$ & $9.7(12)$ & 0.15 & 0.023 \\
Heart failure & $0(0)$ & $2.2(2)$ & $3.8(3)$ & $8.1(10)$ & 0.030 & 0.007 \\
CV mortality & $2.9(2)$ & $2.2(2)$ & $3.8(3)$ & $4.8(6)$ & 0.760 & 0.350 \\
Stroke & $0(0)$ & $1.1(1)$ & $3.8(3)$ & $2.4(3)$ & 0.350 & 0.620 \\
All-cause mortality & $2.9(2)$ & $2.2(2)$ & $6.3(5)$ & $6.5(8)$ & 0.380 & 0.250 \\
\hline
\end{tabular}

*p value in the comparison between the four groups; $\dagger p$ value of the comparison between known diabetics and all the remaining patients. Absolute numbers of events are provided between parentheses; AMI - acute myocardial infarction; CV — cardiovascular

Table 3. Univariate analysis of events on follow-up.

\begin{tabular}{|c|c|c|c|c|c|c|c|c|c|c|}
\hline & \multicolumn{2}{|c|}{ Revascularization } & \multicolumn{2}{|c|}{ Unstable angina } & \multicolumn{2}{|c|}{ Non-fatal AMI } & \multicolumn{2}{|c|}{ Heart failure } & \multicolumn{2}{|c|}{ CV mortality } \\
\hline & No & Yes & No & Yes & No & Yes & No & Yes & No & Yes \\
\hline $\begin{array}{l}\text { Age [years] } \\
\text { (mean) }\end{array}$ & $62.87 \%$ & $63.34 \%$ & $62.63 \%$ & $66.12 \%$ & $63.0 \%$ & $61.95 \%$ & $62.68 \%$ & $68.86 \%^{\dagger}$ & $62.64 \%$ & $70.76 \%$ \\
\hline Gender (male) & $78.10 \%$ & $66.0 \%$ & $78.80 \%$ & $53.10 \%{ }^{\dagger}$ & $77.10 \%$ & $66.70 \%$ & $77.70 \%$ & $60.0 \%$ & $76.80 \%$ & $69.20 \%$ \\
\hline Hypertension & $59.40 \%$ & $66.0 \%$ & $58.80 \%$ & $75.0 \%$ & $59.80 \%$ & $66.70 \%$ & $59.40 \%$ & $80.0 \%$ & $60.5 \%$ & $53.8 \%$ \\
\hline Smoker & $41.60 \%$ & $36.20 \%$ & $43.0 \%$ & $18.80 \%$ * & $41.10 \%$ & $38.10 \%$ & $40.90 \%$ & $40.0 \%$ & $41.5 \%$ & $23.1 \%$ \\
\hline Dyslipidemia & $54.60 \%$ & $57.40 \%$ & $55.50 \%$ & $50.0 \%$ & $54.0 \%$ & $71.4 \%$ & $54.20 \%$ & $73.30 \%$ & $55.3 \%$ & $46.2 \%$ \\
\hline $\begin{array}{l}\text { Creatinine } \\
\text { level on admi- } \\
\text { ssion (mean) } \\
{[\mu \mathrm{mol} / \mathrm{L}]}\end{array}$ & $81.20 \%$ & $91.93 \%$ & $82.21 \%$ & $91.05 \%$ & $82.21 \%$ & $98.12 \%$ & $83.09 \%$ & $79.56 \%$ & $82.21 \%$ & $89.28 \%$ \\
\hline \multicolumn{11}{|c|}{ Carbohydrate metabolism: } \\
\hline Normal & $19.70 \%$ & $14.90 \%$ & $19.10 \%$ & $18.80 \%$ & $19.4 \%$ & $14.3 \%$ & $19.90 \%$ & $0 \%^{\dagger}$ & $19.20 \%$ & $15.40 \%$ \\
\hline Pre-diabetes & $26.70 \%$ & $12.80 \%$ * & $25.50 \%$ & $18.80 \%$ & $25.50 \%$ & $14.30 \%$ & $25.40 \%$ & $13.30 \%$ & $25.20 \%$ & $15.40 \%$ \\
\hline $\begin{array}{l}\text { Newly } \\
\text { detected } \\
\text { diabetes }\end{array}$ & $21.60 \%$ & $23.40 \%$ & $21.80 \%$ & $21.90 \%$ & $22.30 \%$ & $14.30 \%$ & $21.90 \%$ & $20.0 \%$ & $21.80 \%$ & $23.10 \%$ \\
\hline $\begin{array}{l}\text { Known } \\
\text { diabetes }\end{array}$ & $32.10 \%$ & $48.90 \% *$ & $33.60 \%$ & $40.60 \%$ & $32.80 \%$ & $57.0 \% *$ & $32.90 \%$ & $66.70 \%^{\dagger}$ & $33.80 \%$ & $46.20 \%$ \\
\hline \multicolumn{11}{|c|}{ Clinical presentation: } \\
\hline SA & $19.40 \%$ & $27.70 \%$ & $20.0 \%$ & $25.0 \%$ & $19.40 \%$ & $38.10 \% *$ & $19.30 \%$ & $46.70 \%$ * & $20.90 \%$ & $7.70 \%$ \\
\hline ACS & $80.60 \%$ & $72.30 \%$ & $80.0 \%$ & $75.0 \%$ & $80.60 \%$ & $61.90 \% *$ & $80.70 \%$ & $53.30 \%$ * & $79.10 \%$ & $92.30 \%$ \\
\hline EF (mean) & $55.29 \%$ & $56.20 \%$ & $55.26 \%$ & $57.0 \%$ & $55.49 \%$ & $54.0 \%$ & $55.85 \%$ & $45.53 \%^{\dagger}$ & $55.67 \%$ & $47.27 \%$ \\
\hline $\begin{array}{l}\text { SYNTAX } \\
\text { score (mean) }\end{array}$ & $11.30 \%$ & $11.88 \%$ & $11.46 \%$ & $10.43 \%$ & $11.23 \%$ & $13.71 \%$ & $11.22 \%$ & $14.93 \%$ & $11.12 \%$ & $18.11 \%$ \\
\hline
\end{tabular}

${ }^{*} \mathrm{p}<0.05 ; \mathrm{tp}<0.01 ; \mathrm{AMI}$ - acute myocardial infarction; CV — cardiovascular; SA - stable angina; ACS — acute coronary syndrome; $\mathrm{EF}$ - ejection fraction

$\mathrm{p}=0.03)$. We also appreciate a greater incidence of non-fatal myocardial infarction in known-diabetics patients $(12 \%$ vs. $3 \%$, p < 0.023$)$.

We established a comparative analysis of the distribution of clinical, metabolic, and angiographic characteristics compared with the different cardio- vascular events (revascularization, unstable angina, non-fatal heart attack and cardiovascular mortality in follow-up) (Table 3). Among the patients who required a new revascularization in follow-up, there was a lower percentage of pre-diabetics $(12.8 \%$ of pre-diabetics in the patients who needed new 
Table 4. Multivariate analysis.

\begin{tabular}{lccc}
\hline & Odds ratio & $95 \% \mathbf{C l}$ & $\mathbf{P}$ \\
\hline Revascularization: Known diabetes & 2.03 & $1.09-3.77$ & 0.025 \\
Unstable angina: Gender (male) & 0.30 & $0.14-0.64$ & 0.002 \\
Non-fatal AMI: Known diabetes & 2.70 & $1.10-6.60$ & 0.029 \\
Heart failure: & & & 0.022 \\
$\quad$ Known diabetes & 3.82 & $1.21-12.03$ & 0.003 \\
ACS as clinical presentation & 0.17 & $0.05-0.55$ & 0.001 \\
Ejection fraction & 0.93 & $0.90-0.97$ & 0.04 \\
Cardiovascular mortality: & & & 0.02 \\
$\quad$ Age & 1.07 & $1.00-1.14$ & $1.00-1.14$ \\
$\quad$ SYNTAX score & 1.07 & & \\
\hline
\end{tabular}

$\mathrm{Cl}$ - confidence interval; AMI - acute myocardial infarction; ACS - acute coronary syndrome

revascularization and $26.7 \%$ among those who did not need one, $\mathrm{p}=0.04$ ), a greater proportion of known diabetics $(48.9 \%$ in patients revascularized during follow-up vs. $32.1 \%$ among the non-revascularized), and a lower proportion of males, although statistical significance was not reached ( $66 \%$ vs. $78.1 \%, \mathrm{p}=0.06)$. Among the patients who suffered AMI during the follow-up period, there was a higher proportion of known diabetics (57\% vs. $32.8 \%, \mathrm{p}=0.02$ ), and an initial clinical presentation as stable angina was more frequent than in patients who did not suffer infarction in follow-up (38.1 vs. $19.4, \mathrm{p}=0.03$ ). Patients readmitted for infarction presented a higher average SYNTAX score, without statistical significance being reached (13.71 vs. $11.23, \mathrm{p}=0.15$ ).

Readmission for HF was less frequent among the patients with normal glucose metabolism, although statistical significance was not reached, more frequent among the known diabetics $(66.7 \%$ vs. $32.9 \%, \mathrm{p}=0.007)$ and in patients with a lower $\operatorname{LVEF}(45.53 \pm 12.77$ vs. $55.85 \pm 11.40, \mathrm{p}=0.001)$. The SYNTAX score was higher in patients who presented HF, although without statistical significance (11.22 vs. $14.93, \mathrm{p}=0.07)$.

The variables related with mortality in follow-up were age $(70.76 \pm 7.04$ years in patients who died vs. $62.64 \pm 10.78$ in remaining patients, $\mathrm{p}=0.007)$ and the SYNTAX score $(18.11 \pm 9.13$ vs. $11.12 \pm 7.66, \mathrm{p}=0.001$ ).

In the multivariate analysis (Table 4), pre-diabetes and newly detected diabetes were not predictors of any cardiovascular events in follow-up (Table 4). Among glucose metabolism impairments, only a history of known diabetes was an independent predictor of revascularization (OR 2.03, 95\% CI 1.09-3.77, $\mathrm{p}=0.025)$, non-fatal AMI (OR 2.70, $95 \%$ CI 1.10-6.60, $p=0.029)$ and of readmission for
HF during follow-up (OR 3.82, 95\% CI 1.21-12.03, $\mathrm{p}=0.022$ ).

\section{Discussion}

This prospective study shows high prevalence of impaired glucose metabolism in patients undergoing PCI and its connection to the incidence of cardiovascular events, with known diabetes as the only glucose metabolism impairment that is an independent predictor of revascularization, non-fatal infarction and HF during follow-up.

Eighty-one percent of the patients in the series presented impaired glucose metabolism, of which $35.3 \%$ were previously diagnosed diabetics, $21.4 \%$ newly detected diabetics and $24.3 \%$ pre-diabetics, as defined by recently published ADA diagnostic criteria [8].

The prevalence of impaired glucose metabolism described in previous studies [14-17] in patients with previously unknown CVD is high, between $16 \%$ and $32 \%$ of newly detected diabetics and $25-34 \%$ of pre-diabetics depending on the different series reported and the diagnostic criterion employed. In our research, the prevalence of high impairment is similar to that which has been described, but it should be noted that the timing of the OGTT is important: the following morning, as in our research, or two weeks afterwards [14], since the results may be contradictory [18]. The reasons for this could be an increase in stress regulation for the coronary angiography and the OGTT, concomitant medication, inactivity and low-carbohydrate diet during the preceding days, as has been described [18].

The deleterious consequences of impaired glucose metabolism in patients with ACS and no known history of DM have been extensively 
described on many occasions in research that has carried out screening without use of the OGTT [19, 20]. Studies carried out in the general population show the predictive capacity of the tolerance test for cardiovascular events and mortality [21, 22] and the OGTT has been used to diagnose DM $[10,11]$.

However, evidence about the prognostic information provided by the tolerance test in ischemic patients after percutaneous coronary revascularization is scarce. In 2004, Bartnik et al. [22] published research on a series of 168 AMI patients with no known history of DM. The presence of abnormal glucose tolerance, together with a history of heart attack, was the strongest predictor of cardiovascular events, with a median follow-up of 34 months. A short time later, the results of a series of 4,676 patients from the Euro Heart Survey on diabetes and the heart were reported [23]. Known diabetes was the strongest predictor of events, followed by newly detected diabetes with a lower OR. However, impaired fasting glucose and glucose intolerance were not predictors of events in follow-up. De la Hera et al. [15] carried out a 12 month follow-up of 662 ischemic patients (both stable and NSTE-ACS) who underwent PCI, with an OGTT administered to patients with no known history of DM 2 weeks after discharge. Newly detected DM was not a prognostic predictor in this series. The main differences between these studies are the timing to do the OGTT and the context (PCI in modern era or previous era of myocardial infarction with low rate of revascularization): the day after $\mathrm{PCI}$ in the present study, 2 weeks later as stated by de la Hera et al. [15] (ambulatory setting post-PCI), or the day of discharge in old era of myocardial infarction as stated by Bartnik et al. [22].

It should therefore be considered that, although carrying out an OGTT on ischemic patients provides relevant information [24, 25], $\mathrm{PCI}$ is probably not the most suitable context to extract prognostic information about the detection of impaired glucose metabolism that is useful in the short-term clinical management of the patient. The reasons for this may be methodological, as this is a population at low risk of cardiovascular events; they may also be physiopathological as more time is needed in the progression of diabetes for coronary lesions to be produced [26]; or finally, the diagnosis of these impairments may be due more to the situation of stress than to the underlying cardiac pathology (which alters the tolerance test results) [17] than to the etiopathogenic reasons that lead to DM.

The use of simpler, faster, and more reproducible screening tools such as fasting glucose and
$\mathrm{HbA}_{1 \mathrm{c}}$, in conjunction with a global approach to other cardiovascular risk factors may be a more suitable focus within the context of PCI.

\section{Conclusions}

In conclusion, in patients undergoing PCI, carrying out screening for impaired glucose metabolism by means of the determination of fasting glucose and the OGTT allows the detection of a high proportion of glucose abnormalities regulations. However, among glucose metabolism disorders, previously known diabetes is the only independent predictor of cardiovascular events during follow-up.

\section{Acknowledgements}

The authors wish to thank all the patients and nursing staff of the Cardiology Service of the Hospital Universitario Virgen de la Victoria for their collaboration. We also thank Olga Perez Gonzalez for the statistical support and Linda Silvester, Stilogo S.C., for the English language version of the text. This study was undertaken with help from an FIS grant from the Instituto de Salud Carlos III (PI 05/05849) and research grants from the Consejería de Salud de la Junta de Andalucía (No. Exp: 0092/2005). This study also received partial financial support from the RIC (Cardiovascular Research $\mathrm{REd})$. The project was awarded with a research grant from Bayer-Spanish Society of Cardiology (2006) and Andalucian Society of Cardiology (SAC), CIBER Fisiopatología de la Obesidad y Nutrición $(\mathrm{CB} 06 / 03)$ is an ISCIII project.

\section{Conflict of interest: None declared}

\section{References}

1. Onuma Y, Kukreja N, Ramcharitar S et al. Interventional treatment in diabetics in the era of drug-eluting stents and compliance to the ESC guidelines: Lessons learned from the Euro Heart Survey Programme. Eurointervention, 2009; 4: 578-587.

2. Roger VL, Go AS, Lloyd-Jones DM et al. Heart disease and stroke statistics: 2012 update: A report from the American Heart Association. Circulation, 2012; 125: e2-e220.

3. Khawaja FJ, Rihal CS, Lennon RJ et al. Temporal trends (over 30 years), clinical characteristics, outcomes, and gender in patients $\leq 50$ years of age having percutaneous coronary intervention. Am J Cardiol, 2011; 107: 668-674.

4. Bartnik M, Malmberg K, Norhammar A et al. Newly detected abnormal glucose tolerance: An important predictor of long-term outcome after myocardial infarction. Eur Heart J, 2004; 25: 1990-1997.

5. Kuramitsu S, Yokoi H, Domei T et al. Impact of post-challenge hyperglycemia on clinical outcomes in Japanese patients with stable angina undergoing percutaneous coronary intervention. Cardiovasc Diabetol, 2013; 7: 74. 
6. Anselmino M, Ohrvik J, Malmberg K et al. Glucose lowering treatment in patients with coronary artery disease is prognostically important not only in established but also in newly detected diabetes mellitus: A report from the Euro Heart Survey on Diabetes and the Heart. Eur Heart J, 2008; 29: 177-184.

7. Rydén L, Standl E, Bartnik M et al. Guidelines on diabetes, pre-diabetes, and cardiovascular diseases: executive summary. The Task Force on Diabetes and Cardiovascular Diseases of the European Society of Cardiology (ESC) and the European Association for the Study of Diabetes (EASD). Eur Heart J, 2007; 28: 88-136.

8. American Diabetes Association. Diagnosis and classification of diabetes mellitus. Diabetes Care, 2011; 34: S62-S69.

9. van der Horst IC, Nijsten MW, Vogelzang M et al. Persistent hyperglycemia is an independent predictor of outcome in acute myocardial infarction. Cardiovasc Diabetol, 2007; 6: 2.

10. Barrett-Connor E and Ferrara A. Isolated postchallenge hyperglycemia and the risk of fatal cardiovascular disease in older women and men. The Rancho Bernardo Study. Diabetes Care, 1998; 21: 1236-1239.

11. Anand SS, Dagenais GR, Mohan V et al. Glucose levels area associated with cardiovascular disease and death in an international cohort of normal glycaemic and dysglycaemic men and women: the EpiDREAM cohort study. Eur J Prev Cardiol, 2012; 19: 755-764.

12. Rana JS, Venkitachalam L, Selzer F et al. Evolution of percutaneous coronary intervention in patients with diabetes: A report from the National Heart, Lung and Blood Institute-sponsored PTCA (1985-1986) and Dynamic (1997-2006) Registries. Diabetes Care, 2010; 33: 1976-1982.

13. Sianos G, Morel MA, Kappetein AP et al. The SYNTAX score: An angiographic tool grading the complexity of coronary artery disease. Eurointervention, 2005; 1: 219-227.

14. Tenerz A, Norhammar A, Silveira A et al. Diabetes, insulin resistance and the metabolic syndrome in patients with acute myocardial infarction without previously known diabetes. Diabetes Care, 2003; 6: 2770-2776.

15. de la Hera JM, Delgado E, Hernández E et al. Prevalence and outcome of newly detected diabetes in patients who undergo percutaneous coronary intervention. Eur Heart J, 2009; 30: 2614-2621.
16. Norhammar A, Tenerz A, Nilsson G et al. Glucose metabolism in patients with acute myocardial infarction and no previous diagnosis of diabetes mellitus: A prospective study. Lancet, 2002; 359: 2140-2144.

17. Taubert G, Winkelmann BR, Schleiffer T et al. Prevalence, predictors and consequences of unrecognized diabetes mellitus in 3266 patients scheduled for coronary angiography. Am Heart J, 2003; 145: 285-291.

18. Jiménez-Navarro MF, Garcia-Pinilla JM, Garrido-Sanchez L et al. Poor reproducibility of the oral glucose tolerance test in the diagnosis of diabetes during percutaneous coronary intervention. Int J Cardiol, 2010; 142: 245-249.

19. Wallander M, Malmberg K, Norhammar A et al. Oral glucose tolerance test: A reliable tool for early detection of glucose abnormalities in patients with acute myocardial infarction in clinical practice. Diabetes Care, 2008; 31: 36-38.

20. Norhammar AM, Rydén L, Malmberg K. Admission plasma glucose: Independent risk factor for long-term prognosis after myocardial infarction even in nondiabetic patients. Diabetes Care, 1999; 22: 1827-1831.

21. The DECODE Study Group; on behalf of the European Diabetes Epidemiology Group.: Glucose tolerance and cardiovascular mortality. Comparison of fasting and 2-hour diagnostic criteria. Arch Intern Med, 2001; 161: 397-404.

22. Bartnik M, Malmberg K, Hamsten A et al. Abnormal glucose tolerance: A common risk factor in patients with acute myocardial infarction in comparison with population-based controls. J Intern Med, 2004; 256: 288-297.

23. Lenzen M, Ryden L, Ohrvik J et al. Diabetes known or newly detected, but not impaired glucose regulation, has a negative influence on 1-year outcome in patients with coronary artery disease: A report from the Euro Heart Survey on diabetes and the heart. Eur Heart J, 2006; 27: 2969-2974.

24. Qiao Q, Pyörälä K, Pyörälä M et al. Two-hour glucose is a better risk predictor for incident coronary heart disease and cardiovascular mortality than fasting glucose. Eur Heart J, 2002; 23: 1267-1275.

25. Sattar N. Revisiting the links between glycaemia, diabetes and cardiovascular disease. Diabetologia, 2013; 56: 688-695.

26. Barrett-Connor E. The oral glucose tolerance test, revisited. Eur Heart J, 2002; 23: 1229-1231. 